\title{
Acute Chagas disease in El Salvador 2000-2012 - Need for surveillance and control
}

\author{
Emi Sasagawa ${ }^{1 /+}$, Ana Vilma Guevara de Aguilar ${ }^{2}$, Marta Alicia Hernández de Ramírez ${ }^{2}$ \\ José Eduardo Romero Chévez ${ }^{3}$, Jun Nakagawa ${ }^{4}$, Rafael Antonio Cedillos ${ }^{5}$, Kiyoshi Kita ${ }^{1}$ \\ ${ }^{1}$ Department of Biomedical Chemistry ${ }^{4}$ Department of International Community Health, School of International Health, \\ Graduate School of Medicine, The University of Tokyo, Tokyo, Japan ${ }^{2}$ Unidad de Vigilancia Laboratorial \\ ${ }^{3}$ Unidad de Vigilancia de Enfermedades Vectorizadas, Ministerio de Salud, San Salvador, El Salvador \\ ${ }^{5}$ Consejo de Investigaciones Científicas, Universidad de El Salvador, San Salvador, El Salvador
}

\begin{abstract}
Several parasitological studies carried out in El Salvador between 2000-2012 showed a higher frequency of acute cases of Chagas disease than that in other Central American countries. There is an urgent need for improved Chagas disease surveillance and vector control programs in the provinces where acute Chagas disease occurs and throughout El Salvador as a whole.
\end{abstract}

Key words: acute Chagas disease - El Salvador 2000-2012 - surveillance and control

The high incidence of acute Chagas disease in El Salvador has been known for several years. Previous studies have suggested that acute cases of Chagas disease are rarely observed in Latin American countries (Dias \& Schofield 1999) because most cases are asymptomatic, with only 1-2\% of infected individuals experiencing symptoms (Coura 2007). Even though the possibility of contracting the parasite by ingestion of contaminated fruit was recently reported in Venezuela (Alarcón de Noya et al. 2010), oral transmission of Trypanosoma cruzi has not been reported in El Salvador or other Central American countries. As fewer than five acute cases are reported annually throughout the rest of Central America, the reason for the large number of acute cases in El Salvador is unclear.

In most cases, individuals exhibiting symptoms of infection, including dermatologic manifestations of chagoma or Romaña's sign, fever and malaise or who are suspected of having acute Chagas disease are referred to a health facility. Specimens collected from these individuals are sent to the nearest laboratory for examination by either direct microscopic examination of fresh blood or by the Strout method. All positive specimens are sent to the Central Laboratory of the Ministry of Health for confirmation and all acute cases are treated with nifurtimox under the supervision of a physician.

The annual number of acute cases reported between 2000-2012 in each province, is shown in Table. The data presented here are secondary data collected by health personnel rather than by researchers during a formal research study. As can be observed, 731 acute cases were

doi: $10.1590 / 0074-0276140416$

Financial support: Ministry of Health of El Salvador

+ Corresponding author: ebodo77@yahoo.co.jp

Received 24 August 2013

Accepted 23 December 2013 detected in both children and adults over 13 years. The annual number of patients with acute Chagas disease declined from 117 in 2007 to 16 in 2012. In 2011, 50\% of the cases occurred in children aged zero-nine years and $91.7 \%$ of the cases occurred in individuals younger than 20 years of age.

Several factors may have contributed to the effective detection of acute Chagas disease cases, including (i) improved health facility access, permitted by small territories with a high density of medical facilities, (ii) the presence of trained health personnel who can recognise the diagnostic indicators of acute cases (Romaña's signs and chagoma) and (iii) the presence of health promoters, who are each assigned 200 families and are required to make routine house visits to implement public health activities at least once a month. Although these favourable conditions allow for the detection of acute cases, the factors responsible for the high number of acute cases has not been determined.

It is well known that successful vector control interventions have led to a reduced seroprevalence, followed by a decline in the incidence of acute infection (Dias et al. 2002). In contrast, a relatively high infestation rate of Triatoma dimidiata and serological prevalence for $T$. cruzi in El Salvador compared to that in neighbouring countries may be associated with a high incidence of acute infection. A 2008 entomological study of communities where insecticide spraying had not been performed found a mean $T$. dimidiata infestation rate of $23.4 \%$, ranging from $15.2 \%$ in the Morazán province to $44.9 \%$ in San Miguel in El Salvador, to $4.3 \%$ in the Honduras (Aiga et al. 2012). In Guatemala, the infestation rate was recorded as $10.3 \%$ between $2000-2003$, during which no spraying had occurred, but it decreased to $0.7 \%$ after a second cycle of spraying was performed between 20012005 (Hashimoto et al. 2012). Serological testing of children under 16 years of age in 2008 identified only one serologically positive case for T. cruzi $(0.03 \%)$ in Honduras, compared to $30(1.11 \%)$ in El Salvador (Aiga et al. 2012). Nevertheless, a serological study of children un- 
TABLE

Number of acute Chagas cases reported per year by province, 2000-2012

\begin{tabular}{lccccccccccccccc}
\hline Region & Province & 2000 & 2001 & 2002 & 2003 & 2004 & 2005 & 2006 & 2007 & 2008 & 2009 & 2010 & 2011 & 2012 & Sub-total \\
\hline \multirow{2}{*}{ Western } & Ahuachapan & 3 & 2 & 0 & 2 & 1 & 15 & 18 & 10 & 14 & 7 & 3 & 5 & 3 & 83 \\
& Santa Ana & 29 & 4 & 3 & 2 & 9 & 21 & 9 & 10 & 17 & 7 & 6 & 14 & 7 & 138 \\
& Sonsonate & 6 & 2 & 2 & 0 & 10 & 16 & 9 & 7 & 8 & 11 & 2 & 1 & 1 & 75 \\
\multirow{5}{*}{ Central } & Chalatenango & 0 & 0 & 0 & 0 & 0 & 3 & 1 & 4 & 6 & 0 & 0 & 0 & 0 & 14 \\
& La Libertad & 1 & 1 & 4 & 0 & 4 & 2 & 1 & 1 & 0 & 8 & 0 & 1 & 2 & 25 \\
\multirow{5}{*}{ Metropolitan } & San Salvador & 6 & 19 & 5 & 19 & 17 & 24 & 32 & 60 & 20 & 8 & 0 & 0 & 1 & 211 \\
Paracentral & Cuscatlan & 0 & 1 & 0 & 0 & 0 & 3 & 7 & 2 & 4 & 3 & 2 & 0 & 1 & 23 \\
& La Paz & 0 & 0 & 0 & 0 & 0 & 2 & 0 & 0 & 5 & 2 & 0 & 0 & 0 & 9 \\
& San Vicente & 0 & 0 & 1 & 0 & 1 & 0 & 0 & 0 & 1 & 0 & 0 & 0 & 0 & 3 \\
\multirow{2}{*}{ Eastern } & Cabanas & 0 & 0 & 16 & 0 & 0 & 2 & 2 & 2 & 2 & 3 & 0 & 0 & 0 & 27 \\
& Usulutan & 0 & 0 & 0 & 0 & 2 & 4 & 5 & 0 & 2 & 4 & 2 & 1 & 0 & 20 \\
& San Miguel & 0 & 0 & 4 & 0 & 0 & 17 & 32 & 19 & 9 & 2 & 1 & 2 & 1 & 87 \\
& Morazan & 0 & 0 & 0 & 0 & 8 & 0 & 0 & 1 & 0 & 2 & 0 & 0 & 0 & 11 \\
Total & La Union & 0 & 0 & 0 & 0 & 2 & 1 & 0 & 1 & 1 & 0 & 0 & 0 & 0 & 5 \\
\hline
\end{tabular}

source: Department of Parasitology, Central Laboratory of the Ministry of Health in El Salvador.

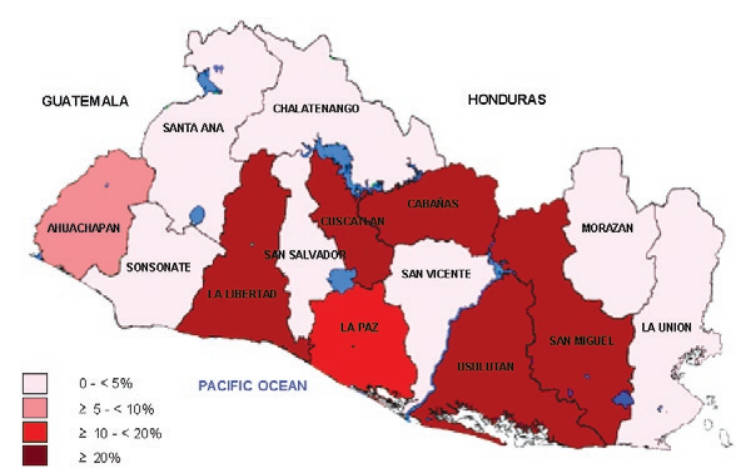

Dispersion index of Triatoma dimidiata by province, in 2011. Source: Department of Parasitology, Central Laboratory of the Ministry of Health in El Salvador.

der six years of age found the seroprevalence in El Salvador (0.36\%) between 1999-2000 (Cedillos et al. 2002) to be slightly lower than that in Guatemala $(0.5 \%)$ between 2004-2005 (Hashimoto et al. 2012). However, routine house visits for active search of triatomine bugs by health promoters and health personnel of a vector-borne disease control program revealed that half of El Salvador has a high $T$. dimidiata dispersion index (Figure). This finding implies the need for urgent improvements to the surveillance and vector control programs are required in the provinces where acute Chagas disease occurs and throughout the rest of the country.

Two limitations of this study were the use of secondary data and the inability to obtain data regarding the clinical manifestation and demographic characteristics of the subjects for further analysis. A third limitation was that the cases reported were only those detected by chance because most patients are asymptomatic during the acute phase and thus, these data represent only a small proportion of all acute Chagas disease cases. Further understanding of the epidemiology of Chagas disease requires assessment of the geographical distribution of $T$. dimidiata and its infestation rate.

This study was performed by analysing the existing secondary data without personal information. Although this study was not presented before the ethics review board, we believe that those data will contribute to the improvement of Chagas disease control activities in El Salvador and Central American countries.

\section{ACKNOWLEDGEMENTS}

To the support provided by the Ministry of Health of El Salvador and JICA, and to the advice provided by Dr Chizuru Misago and Dr Ken Hashimoto.

\section{REFERENCES}

Aiga H, Sasagawa E, Hashimoto K, Nakamura J, Zúniga C, Chévez JE, Hernández HM, Nakagawa J, Tabaru Y 2012. Chagas disease: assessing the existence of a threshold for bug infestation rate. $\mathrm{Am}$ J Trop Med Hyg 86: 972-979.

Alarcón de Noya BA, Díaz-Bello Z, Colmenares C, Ruiz-Guevara R, Mauriello L, Zavala-Jaspe R, Suarez JA, Abate T, Naranjo L, Paiva M, Rivas L, Castro J, Márques J, Mendoza I, Acquatella H, Torres J, Noya O 2010. Large urban outbreak of orally acquired acute Chagas disease at a school in Caracas, Venezuela. J Infect Dis 201: 1308-1315.

Cedillos RA, Francia H, Soundy-Call J, Ascencio G, Valcarcel-Novo M 2002. Estudio epidemiológico de la infección por Trypanosoma cruzi en El Salvador, Centro América. Available from: cic. ues.edu.sv/2/1/22-32. 
Coura JR 2007. Chagas disease: what is known and what is needed - A background article. Mem Inst Oswaldo Cruz 102 (Suppl. I): 113-122.

Dias JCP, Schofield CJ 1999. The evolution of Chagas disease (American trypanosomiasis) control after 90 years since Carlos Chagas discovery. Mem Inst Oswaldo Cruz 94 (Suppl. I): 103-121.
Dias JCP, Silveira AC, Schofield CJ 2002. The impact of Chagas disease control in Latin America - A Review. Mem Inst Oswaldo Cruz 97: 603-612.

Hashimoto K, Álvarez H, Nakagawa J, Juarez J, Monroy C, CordónRosales C, Gil E 2012. Vector control intervention towards interruption of transmission of Chagas disease by Rhodnius prolixus, main vector in Guatemala. Mem Inst Oswaldo Cruz 107: 877-887. 